\title{
Exploring the mRNA expression level of $R E L N$ in peripheral blood of schizophrenia patients before and after antipsychotic treatment
}

\author{
Jiajun Yin ${ }^{1}$, Yana $\mathrm{Lu}^{2}$, Shui Yu ${ }^{1}$, Zhanzhan Dai ${ }^{2}$, Fuquan Zhang ${ }^{3^{*}}$ and Jianmin Yuan ${ }^{1 *}$ (D)
}

\begin{abstract}
Background: The Reelin (RELN) gene encodes the protein reelin, which is a large extracellular matrix glycoprotein that plays a key role in brain development. Additionally, this protein may be involved in memory formation, neurotransmission, and synaptic plasticity, which have been shown to be disrupted in schizophrenia (SCZ). A decreasing trend in the expression of RELN mRNA in the brain and peripheral blood of SCZ patients has been observed. There is a need to determine whether changes in RELN mRNA expression in SCZ patients are the result of long-term antipsychotic treatment rather than the etiological characteristics of schizophrenia. The expression levels of RELN mRNA in the peripheral blood of 48 healthy controls and $30 \mathrm{SCZ}$ patients before and after 12-weeks of treatment were measured using quantitative real-time PCR.

Results: The expression levels of RELN mRNA in the SCZ group were significantly lower than that of healthy controls; however, after 12-weeks of antipsychotic treatment, RELN mRNA levels were significantly increased in the SCZ group.

Conclusion: The up-regulation of RELN mRNA expression was current in SCZ patients after antipsychotic treatment, suggesting that the changes in RELN mRNA expression were related to the effect of the antipsychotic treatment.
\end{abstract}

Keywords: RELN, SCZ, Antipsychotic treatment

\section{Background}

Schizophrenia (SCZ) is a common and severe mental disorder, with a lifetime prevalence estimate of 4.0 (1.612.1) per 1000 persons and a median incidence of 15.2 per 100,000 individuals $[1,2]$. The disease is characterized by positive and negative symptoms, including

\footnotetext{
* Correspondence: zhangfa@njmu.edu.cn; 13358118723@163.com; yjmpaper@163.com

${ }^{3}$ Department of Psychiatry, The Affiliated Brain Hospital of Nanjing Medical University, 264 Guangzhou Road, Nanjing 210029, Jiangsu Province, P.R. China

'Brain Science Basic Laboratory, The Affiliated Wuxi Mental Health Center with Nanjing Medical University, 156 Qianrong Road, Wuxi 214151, Jiangsu Province, P.R. China

Full list of author information is available at the end of the article
}

abnormalities in cognitive function and personality, such as language, thought, perception, emotion, and selfawareness. Despite the wide prevalence of SCZ and many decades of major progress, the underlying etiology of this disease remains elusive.

In contemporary practice, clinicians still diagnose clinical symptoms and evaluate progress and treatment responses based on clinical symptoms. The development of objective tests for the diagnosis of SCZ or monitoring of drug reactions is essential to providing early intervention for patients, which is beneficial for improving prognosis. In addition, several studies have shown that gene expression causes changes in different tissues of patients

C C The Author(s). 2020 Open Access This article is licensed under a Creative Commons Attribution 4.0 International License, which permits use, sharing, adaptation, distribution and reproduction in any medium or format, as long as you give appropriate credit to the original author(s) and the source, provide a link to the Creative Commons licence, and indicate if changes were made. The images or other third party material in this article are included in the article's Creative Commons licence, unless indicated otherwise in a credit line to the material. If material is not included in the article's Creative Commons licence and your intended use is not permitted by statutory regulation or exceeds the permitted use, you will need to obtain permission directly from the copyright holder. To view a copy of this licence, visit http://creativecommons.org/licenses/by/4.0/ The Creative Commons Public Domain Dedication waiver (http://creativecommons.org/publicdomain/zero/1.0/) applies to the data made available in this article, unless otherwise stated in a credit line to the data. 
with SCZ [3-8]. The cystine/glutamate antiporter system $\mathrm{x}_{\mathrm{c}}{ }^{-}$is a potential target for the treatment of SCZ, which releases glutamate into synapses and thus increases glutaminergic neurotransmission $[9,10]$. A human study also showed that the peripheral expression of mRNA of the two subunits of system $\mathrm{x}_{\mathrm{c}}{ }^{-}$, solute carrier 3A2(SLC3A2) and solute carrier 7A11(SLC7A11), was lower in SCZ than healthy individuals [11]. Since the detection of mRNA in peripheral whole blood is accessible and non-invasive, the pattern of gene expression serves as a potential biomarker for SCZ diagnosis and therapeutic monitoring [12].

The RELN gene is located on chromosome $7 \mathrm{q} 22$, and it encodes the protein reelin, a large extracellular matrix glycoprotein that plays a key role in brain development from neuronal migration to dendritic spine formation and synaptic transmission [13-15]. Moreover, it may be involved in memory formation, neurotransmission, and synaptic plasticity [16, 17], as well as SCZ [18]. The earliest direct evidence was based on the postmortem studies of patients with SCZ, which revealed that RELN mRNA was reduced up to $50 \%$ in several regions of the brain $[19,20]$. Additionally, RELN had been shown to be expressed in organ systems, inter alia in human blood, liver, pancreas, breast and intestines [21-26]. A recent study determined that the patients with SCZ had higher level of RELN gene methylation compared to healthy controls, leading to a subsequent 25 -fold decrease in RELN expression in the methylated group [27]. The role of RELN was associated with SCZ in an earlier large genome-wide association study (GWAS), which found that the polymorphism rs7341475 accounted for a 1.4fold increase in the risk of the disease in women [28]. Moreover, this gene variant was associated with working memory, episodic memory, and executive functioning in the nuclear families of one member with SCZ [29]. Subsequently, a growing number of studies have reported that a number of single nucleotide polymorphisms (SNPs) in the RELN gene were associated with the pathogenesis and/or severity of clinical symptoms of SCZ [30-37]. Hence, based on the low level of RELN in SCZ patients and the relationship between its genetic variation and SCZ, RELN may play a pathogenic role in SCZ [38]. This view was further supported by heterozygous reelin mouse model. Although the mice had fewer neuroanatomical defects, they had cognitive abnormalities of some common psychotic disorders [39].

In studies on SCZ, the healthy controls were not treated with antipsychotic drugs, whereas patients with SCZ were often treated with these drugs. It is important to determine whether changes in RELN gene expression in these patients are the result of long-term antipsychotic treatment or due to etiological characteristics of SCZ. Suzuki et al. reported that the level of the RELN receptor VLDLR in the peripheral blood lymphocytes of patients with SCZ was decreased. After 6 months of antipsychotic treatment, the gene expression increased [40]. Another study showed that protracted treatment with olanzapine resulted in the upregulation of RELN expression in the frontal cortex of rats [41, 42]. However, a previous postmortem study showed no correlation between the levels of RELN mRNA and reelin protein and lifetime doses of antipsychotics drugs [20]. Overall, the regulation of RELN in patients with $\mathrm{SCZ}$ requires broader research including other typical or atypical antipsychotic treatments.

In this study, we investigated the expression of RELN mRNA in whole blood before and after antipsychotic medication in patients with SCZ to explore the therapeutic value of RELN as a biomarker for SCZ.

\section{Methods and methods \\ Subjects}

All participants were unrelated and of the ethnic Han group from the Jiangsu Province of China. The SCZ patients were recruited from the Wuxi Mental Health Center and independently diagnosed by at least two experienced psychiatrists according to the Diagnosis and Statistical Manual of Mental Disorders, 4th ed. (DSM-IV).

A total of 30 patients in the acute stage of SCZ (16 women and 14 men; mean age $=35.87$ years, $S D=10.21$ ) were chosen for this study and included 5 first-episode, 18 drug-naive SCZ patients or recurrent, 7 drug-free SCZ patients with self-withdrawn antipsychotic drugs at least 1 month before enrollment (Table 1). All patients participating in the study were treated with one of the oral second generation or atypical antipsychotics (SGA) and received continuous drug therapy for 12 weeks after baseline assessments. The psychopathology of all patients was assessed through an oral case history interview and psychiatric interview using the Positive and Negative Syndrome Scale (PANSS) [43] at baseline and 12 weeks. Among the 30 patients, 20 were treated with risperidone, 6 with olanzapine, 2 with clozapine, 1 with quetiapine, and 1 with aripiprazole. All patients were administered one of the five SGAs once daily, starting with an initial dose and increasing to a curative dose over the subsequent 2-4 weeks. All patients demonstrated clinical improvement as evidenced by more than a $25 \%$ reduction in the PANSS score. A total of 48 healthy controls

Table 1 Demographic characteristics of the study participants

\begin{tabular}{llll}
\hline & Control & SCZ & P value \\
\hline Sample size & 48 & 30 & \\
Age (mean \pm SD) & $31.67 \pm 6.75$ & $35.87 \pm 10.21$ & 0.066 \\
Gender (Men: woman) & $17: 31$ & $14: 16$ & 0.323 \\
\hline
\end{tabular}

Abbreviations: Control Healthy control, SCZ Untreated SCZ patients 
(HCs) (31 women and 17 men; mean age $=31.67$ years, $\mathrm{SD}=6.75$ ) without a history of mental health disorders or neurological diseases were recruited from local communities by advertisement (Table 1 ).

There were no significant differences in gender and age between the SCZ and $\mathrm{HC}$ groups. The Ethics Committees of the Wuxi Mental Health Center approved this study, and the study was conducted according to the principles of the Declaration of Helsinki 1975. Written informed consent was obtained from all participants prior to participation in the study.

\section{Analysis of RELN expression by the real-time quantitative PCR (RT-qPCR)}

Whole-blood samples were collected in PAXgene blood RNA tubes (PreAnalytiX QIAGEN/BD, Hombrechtikon, Switzerland) and total RNA was extracted from whole blood samples using PAXgene Blood miRNA Kit (PreAnalytiX QIAGEN/BD, Hombrechtikon, Switzerland) according to the manufacturer's instructions. Reverse transcription was performed using $200 \mathrm{ng}$ of total RNA and the High Capacity RNA-to-cDNA Kit (Thermo Fisher Scientific, Waltham, MA, USA). Real-time quantitative PCR was performed using the primers for RELN, namely, CATGGTTGCAAGTGTGACCC (forward) and AAACCAGGGCCTTACCACTG (reverse) and a SYBR ${ }^{\circ}$ Select Master Mix (Thermo Fisher Scientific, Waltham, MA, USA). The reactions were performed in triplicate for each of the three independent samples using the ViiA 7 Real-Time PCR System (Thermo Fisher Scientific, Waltham, MA, USA) under the following conditions: $95^{\circ} \mathrm{C}$ for $10 \mathrm{~min}$ and 40 cycles each of $95^{\circ} \mathrm{C}$ for $10 \mathrm{~s}$ and $60^{\circ} \mathrm{C}$ for $60 \mathrm{~s}$. The relative expression level of $R E L N$ for each individual after normalization to $A C T B$ was calculated using the comparative $\mathrm{Ct}\left(2^{-\Delta \Delta \mathrm{Ct}}\right)$ method [44]. The primers of $A C T B$ were AAGTCCCT CACCCTCCCAAAAG (forward) and AAGCAATGCT GTCACCTTCCC (reverse).

\section{Statistical analysis}

The Statistical Package for the Social Sciences (SPSS) software version 21.0 (SPSS Inc., Chicago, IL, USA) for statistical analyses. The Student's t-test was used to compare age between the SCZ group and control subjects. Gender differences were measured using Pearson's chi-square test. PANSS scores before and after treatment were compared using the paired t-test.

The differences of RELN mRNA levels between the SCZ group and the healthy control group were analyzed for normality with the Shapiro-Wilk test followed by MannWhitney $\mathrm{U}$ test, and the changes in RELN expression between the SCZ group before and after treatment with antipsychotic medication were analyzed using paired Wilcoxon signed-rank test. All of the $P$ values less than
0.05 were considered statistically significant. Spearman's correlation analysis was used to analyze the relationship between the RELN mRNA levels and the PANSS scores in $\mathrm{SCZ}$ patients before and after treatment.

\section{Results}

The expression levels of RELN mRNA in each subject were validated in the RT-qPCR shown in Fig. 1. The expression levels of RELN mRNA in the whole blood of $30 \mathrm{SCZ}$ patients was significantly lower than that of the 48 healthy controls $(P=0.0476$, Table 2$)$. After 12 weeks of antipsychotic treatment, the expression levels of RELN mRNA in the SCZ patients were significantly increased $(P=0.0384$, Table 2$)$. The analysis of the expression levels of RELN mRNA in specific subgroups found that the RELN mRNA expression level of untreated female SCZ patients was significantly lower than that of the healthy female control group $(P=0.0025$, Table 2$)$.

As shown in Table 3, we still have distinguished one specific drug from the whole class of antipsychotic as RELN mRNA-induced dysregulation. After 12 weeks of olanzapine treatment, RELN mRNA expression level in 6 SCZ patients was significantly increased $(P=0.0313)$.

As shown in Table 4, in the SCZ patients before and after treatment, no significant relationship was found between the RELN mRNA levels and the positive symptom points, negative points, general pathological symptom points, or the total PANSS scores. In addition, we have observed no significant correlations between variation in RELN mRNA expression and the reduction rate of total PANSS scores $(r=-0.09, p=0.638)$.

\section{Discussion}

In this study, we found decreased expression of RELN mRNA in the whole blood of the untreated SCZ patients. This finding is consistent with previous studies in which RELN gene expression was down-regulated in the brain and peripheral blood of SCZ patients [19, 20, 27]. In addition, the study revealed that the RELN mRNA expression levels were significantly upregulated in SCZ patients after 12 weeks of antipsychotic treatment. Fatemi and his colleagues reached a similar conclusion in the frontal cortex of rats [41, 42]. Meanwhile, a similar conclusion was reached in the study of RELNrelated genes in SCZ patients [40]. We still have taken into account the difference in drug treatment, and have distinguished olanzapine from the whole class of antipsychotic as RELN mRNA-induced dysregulation. Hence, the up-regulation of RELN mRNA expression was concurrent with the improvement in symptoms in SCZ patients after treatment, suggesting that the changes in RELN mRNA expression were attributed to the antipsychotic treatment. 


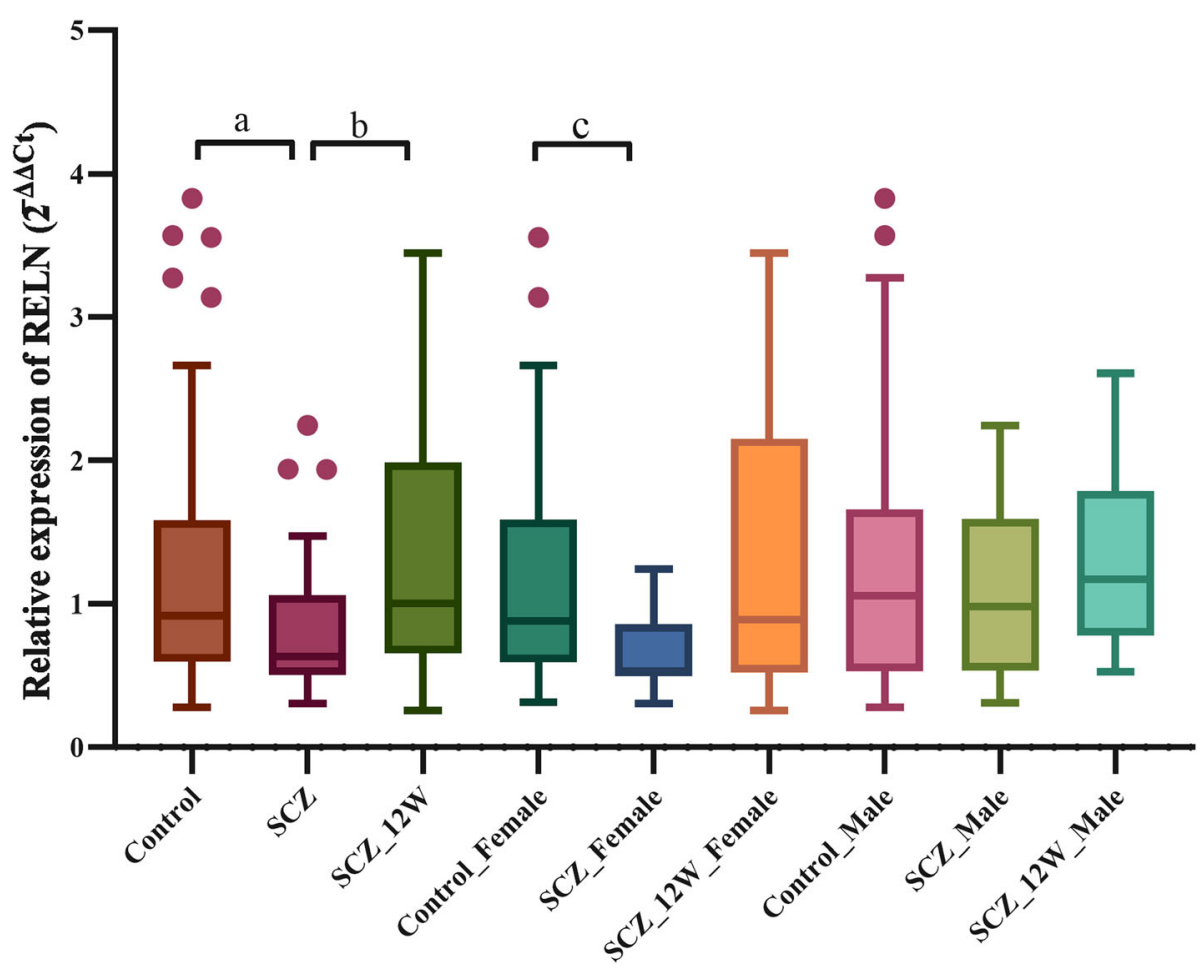

Fig. 1 A Tukey's "box-plot" of the expression levels of RELN in controls and SCZ patients before and after treatment (2 $\left.{ }^{-\triangle \Delta C t}\right)$. a: The expression of RELN mRNA in the whole blood of control subjects was higher than that in SCZ patients (Mann-Whitney $U$ test); b: The expression of RELN mRNA in the whole blood of SCZ_12w patients was higher than that in SCZ patients (paired Wilcoxon signed-rank test); c: In female subgroup, the expression of RELN mRNA in the whole blood of control subjects was higher than that in SCZ patients (Mann-Whitney $U$ test); Control: healthy control; SCZ: untreated SCZ patients; SCZ_12w: SCZ patients after 12 weeks of antipsychotic treatment. The box plots display the median and interquartile range (25th to 75th percentiles), and the whiskers outside the box extend to the highest and lowest value within 1.5 times the interquartile range. Points outside the whiskers are outliers

Table 2 Comparison of RELN expression levels in controls, and SCZ patients before and after treatment $\left(2^{-\Delta \Delta C t}\right)$

\begin{tabular}{|c|c|c|}
\hline & RELN & $P$ \\
\hline \multicolumn{3}{|l|}{ Total } \\
\hline Control (48) & $1.25 \pm 0.13$ & \\
\hline SCZ (30) & $0.86 \pm 0.09$ & $0.0476^{a}$ \\
\hline SCZ_12W (30) & $1.32 \pm 0.15$ & $0.0384^{b}$ \\
\hline \multicolumn{3}{|l|}{ Female } \\
\hline Control (31) & $1.20 \pm 0.14$ & \\
\hline SCZ (16) & $0.64 \pm 0.07$ & $0.0025^{a}$ \\
\hline SCZ_12W (16) & $1.33 \pm 0.24$ & $0.0507^{b}$ \\
\hline \multicolumn{3}{|l|}{ Male } \\
\hline Control (17) & $1.35 \pm 0.28$ & \\
\hline SCZ (14) & $1.10 \pm 0.16$ & $0.9844^{\mathrm{a}}$ \\
\hline SCZ_12W (14) & $1.32 \pm 0.17$ & $0.3575^{b}$ \\
\hline
\end{tabular}

Abbreviations: Control Healthy control, SCZ Untreated schizophrenia patients, SCZ_12w Schizophrenia patients after 12 weeks of antipsychotic treatment; ${ }^{a}$ : comparisons between the untreated schizophrenia patients and healthy control (Mann-Whitney U test); ${ }^{\text {b }}$ : comparisons between the schizophrenia patients after 12 weeks of antipsychotic treatment and untreated schizophrenia patients (paired Wilcoxon signed-rank test); Bold figures indicate $P<0.05$
The main aim of the extensive literature studies is to identify potential biomarkers that play an important role in clinical practice supporting the diagnostic and therapeutic of SCZ [45]. These studies are important for all medical and mental illnesses. However, there are still no reliable biomarkers to support the diagnosis of SCZ that mainly depends on clinical observation. Thus, the identification of biomarkers of SCZ could be ideally incorporated into diagnostic criteria and potentially used to evaluate symptom improvement. Although these potential biomarkers are still in their infancy, it would be

Table 3 Comparison of RELN expression levels in SCZ patients before and after treatment with different antipsychotics $\left(2^{-\Delta \Delta C t}\right)$

\begin{tabular}{llll}
\hline RELN (n) & SCZ & SCZ_12W & $P$ \\
\hline Risperidone (20) & $0.94 \pm 0.13$ & $1.20 \pm 0.15$ & 0.2943 \\
Olanzapine (6) & $0.61 \pm 0.09$ & $1.85 \pm 0.40$ & $\mathbf{0 . 0 3 1 3}$ \\
Others (4) & $0.80 \pm 0.18$ & $1.16 \pm 0.57$ & $>0.9999$ \\
\hline
\end{tabular}

Abbreviations: Others: included $2 \mathrm{SCZ}$ with clozapine, $1 \mathrm{SCZ}$ with quetiapine, and 1 SCZ with aripiprazole. SCZ Untreated schizophrenia patients, SCZ_12w Schizophrenia patients after 12 weeks of antipsychotic treatment; Bold figures indicate $P<0.05$ 
Table 4 Correlation analysis between RELN mRNA levels and PANSS scores in SCZ patients before and after treatment ( $r$ value)

\begin{tabular}{lll}
\hline PANSS & \multicolumn{2}{l}{ RELN mRNA } \\
\cline { 2 - 3 } & $\begin{array}{l}\text { SCZ } \\
(\boldsymbol{n}=\mathbf{3 0})\end{array}$ & $\begin{array}{l}\text { SCZ_12W } \\
(\boldsymbol{n}=\mathbf{3 0})\end{array}$ \\
\hline Total PANSS scores & -0.021 & -0.196 \\
Positive symptom points & -0.114 & -0.177 \\
Negative symptom points & -0.041 & -0.174 \\
General pathological symptom points & 0.131 & -0.246 \\
\hline
\end{tabular}

Abbreviations: SCZ Untreated schizophrenia patients, SCZ 12w Schizophrenia patients after 12 weeks of antipsychotic treatment; All $P$ values $>0.05$

interesting to search for potential biomarkers through blood-based or brain imaging approaches. For instance, G72, functioning as a D-amino acid oxidase (DAAO) activator (DAOA), plays an important role in dysregulation of the glutamate system, and has been found to be a potential biomarker with excellent sensitivity and specificity [45]. Lin et al. demonstrated that the plasma G72 protein levels were significantly increased in both medicated and drug-free patients with SCZ than in healthy controls [46] and the finding has been independently verified [47].

It is worth explicitly noting that the main limitation of this study was the limited sample size, which may reduce the statistical power to compare the level of RELN mRNA expression between different groups. Furthermore, we only measured RELN mRNA expression in peripheral blood; therefore, extrapolating these results to the brain should be treated with caution. These findings will need to be confirmed in future studies that involve a larger sample size. We have compared the expression of RELN mRNA in SCZ patients before and after antipsychotic treatment but did not compare expression of RELN mRNA in healthy controls before and after a 12week time window. Therefore, one limitation of this study was to assess the RELN levels only once in healthy control group.

\section{Conclusions}

Taken together, these results demonstrate that the expression of $R E L N$ is down-regulated in the peripheral blood of untreated SCZ patients, whereas its expression level is significantly up-regulated after 12 weeks of antipsychotic treatment. These findings suggest that changes in $R E L N$ expression are associated with antipsychotic treatment and may provide new clues for understanding the pathogenesis and treatment of SCZ.

\footnotetext{
Abbreviations

SCZ: Schizophrenia; GWAS: Genome-wide association study; SNPs: Single nucleotide polymorphisms; DSM-IV: Diagnosis and Statistical Manual of Mental Disorders, 4th ed.; SGA: The oral second generation or atypical antipsychotics; PANSS: Positive and Negative Syndrome Scale; HCs: Healthy controls; RT-qPCR: Real-time quantitative PCR; $2^{-\Delta \Delta C t}$ : Comparative $C t$; SPSS: The Statistical Package for the Social Sciences.
}

\section{Acknowledgements}

We thank the SCZ patients and healthy controls for their cooperation in the study.

\section{Authors' contributions}

All authors made substantial contributions to conception and design, acquisition of data, or analysis and interpretation of data; took part in drafting the article or revising it critically for important intellectual content; gave final approval of the version to be published; and agree to be accountable for all aspects of the work. The authors read and approved the final manuscript.

\section{Funding}

This work was supported by the Science \&Technology Development Foundation of Wuxi Municipal Science \& Technology Bureau (WX18IIAN033).

\section{Availability of data and materials}

The datasets used and/or analysed during the current study are available from the corresponding author on reasonable request.

\section{Ethics approval and consent to participate}

This study was approved by the Ethics Committees of Wuxi Mental Health Center. The reference number is 2019166. Written informed consent was obtained from all participants prior to participation in the study.

\section{Consent for publication}

Not applicable.

\section{Competing interests}

The authors declare that they have no competing interests.

\section{Author details}

${ }^{1}$ Brain Science Basic Laboratory, The Affiliated Wuxi Mental Health Center with Nanjing Medical University, 156 Qianrong Road, Wuxi 214151, Jiangsu Province, P.R. China. ${ }^{2}$ Department of Psychiatry, The Affiliated Wuxi Mental Health Center with Nanjing Medical University, Wuxi, Jiangsu Province, China. ${ }^{3}$ Department of Psychiatry, The Affiliated Brain Hospital of Nanjing Medical University, 264 Guangzhou Road, Nanjing 210029, Jiangsu Province, P.R. China.

Received: 19 August 2020 Accepted: 28 October 2020

Published online: 06 November 2020

\section{References}

1. McGrath J, Saha S, Chant D, Welham J. Schizophrenia: a concise overview of incidence, prevalence, and mortality. Epidemiol Rev. 2008:30:67-76.

2. Saha S, Chant D, Welham J, McGrath J. A systematic review of the prevalence of schizophrenia. PLoS Med. 2005;2(5):e141.

3. Mellios N, Huang HS, Baker SP, Galdzicka M, Ginns E, Akbarian S. Molecular determinants of dysregulated GABAergic gene expression in the prefrontal cortex of subjects with schizophrenia. Biol Psychiatry. 2009;65(12):1006-14.

4. Datta D, Arion D, Corradi JP, Lewis DA. Altered expression of CDC42 signaling pathway components in cortical layer 3 pyramidal cells in schizophrenia. Biol Psychiatry. 2015;78(11):775-85.

5. Yoshino Y, Kawabe K, Yamazaki K, Watanabe S, Numata S, Mori Y, et al. Elevated TREM2 mRNA expression in leukocytes in schizophrenia but not major depressive disorder. J Neural Transm (Vienna). 2016;123(6):637-41.

6. Xu Y, Yao Shugart Y, Wang G, Cheng Z, Jin C, Zhang K, et al. Altered expression of mRNA profiles in blood of early-onset schizophrenia. Sci Rep. 2016;6:16767.

7. Fromer M, Roussos P, Sieberts SK, Johnson JS, Kavanagh DH, Perumal TM, et al. Gene expression elucidates functional impact of polygenic risk for schizophrenia. Nat Neurosci. 2016;19(11):1442-53.

8. Cai HQ, Catts VS, Webster MJ, Galletly C, Liu D, O'Donnell M, et al. Increased macrophages and changed brain endothelial cell gene expression in the frontal cortex of people with schizophrenia displaying inflammation. Mol Psychiatry. 2020;25(4):761-75

9. Massie A, Boillee S, Hewett S, Knackstedt L, Lewerenz J. Main path and byways: non-vesicular glutamate release by system $x c(-)$ as an important modifier of glutamatergic neurotransmission. J Neurochem. 2015;135(6): 1062-79. 
10. Baker DA, Madayag A, Kristiansen LV, Meador-Woodruff JH, Haroutunian V, Raju I. Contribution of cystine-glutamate antiporters to the psychotomimetic effects of phencyclidine. Neuropsychopharmacology. 2008;33(7):1760-72.

11. Lin $C H$, Lin PP, Lin CY, Lin CH, Huang CH, Huang YJ, et al. Decreased mRNA expression for the two subunits of system $x C(-)$, SLC3A2 and SLC7A11, in WBC in patients with schizophrenia: evidence in support of the hypoglutamatergic hypothesis of schizophrenia. J Psychiatr Res. 2016;72:58-63.

12. Lai CY, Scarr E, Udawela M, Everall I, Chen WJ, Dean B. Biomarkers in schizophrenia: a focus on blood based diagnostics and theranostics. World J Psychiatry. 2016;6(1):102-17.

13. Hartfuss E, Forster E, Bock HH, Hack MA, Leprince P, Luque JM, et al. Reelin signaling directly affects radial glia morphology and biochemical maturation. Development. 2003;130(19):4597-609.

14. Huang CC, D'Arcangelo G. In: Fatemi SH, editor. The Reelin gene and its functions in brain development. Reelin glycoprotein. New York: Springer Science; 2008

15. Niu S, Yabut O, D'Arcangelo G. The Reelin signaling pathway promotes dendritic spine development in hippocampal neurons. J Neurosci. 2008; 28(41):10339-48.

16. Beffert U, Weeber EJ, Durudas A, Qiu SF, Masiulis I, Sweatt JD, et al. Modulation of synaptic plasticity and memory by Reelin involves differential splicing of the lipoprotein receptor Apoer2. Neuron. 2005;47(4):567-79.

17. Herz J, Chen Y. Reelin, lipoprotein receptors and synaptic plasticity. Nat Rev Neurosci. 2006;7(11):850-9.

18. Falkai P, Rossner MJ, Schulze TG, Hasan A, Brzozka MM, Malchow B, et al. Kraepelin revisited: schizophrenia from degeneration to failed regeneration. Mol Psychiatry. 2015;20(6):671-6.

19. Impagnatiello F, Guidotti AR, Pesold C, Dwivedi Y, Caruncho H, Pisu MG, et al. A decrease of reelin expression as a putative vulnerability factor in schizophrenia. Proc Natl Acad Sci. 1998;95(26):15718-23.

20. Guidotti A, Auta J, Davis JM, Di-Giorgi-Gerevini V, Dwivedi Y, Grayson DR, et al. Decrease in reelin and glutamic acid decarboxylase67 (GAD67) expression in schizophrenia and bipolar disorder: a postmortem brain study. Arch Gen Psychiatry. 2000;57(11):1061-9.

21. Smalheiser NR, Costa E, Guidotti A, Impagnatiello F, Auta J, Lacor P, et al. Expression of reelin in adult mammalian blood, liver, pituitary pars intermedia, and adrenal chromaffin cells. Proc Natl Acad Sci U S A. 2000; 97(3):1281-6.

22. Samama B, Boehm N. Reelin immunoreactivity in lymphatics and liver during development and adult life. Anat Rec A Discov Mol Cell Evol Biol. 2005;285(1):595-9.

23. Fatemi SH, Kroll JL, Stary JM. Altered levels of Reelin and its isoforms in schizophrenia and mood disorders. Neuroreport. 2001;12(15):3209-15.

24. Sato N, Fukushima N, Chang R, Matsubayashi H, Goggins M. Differential and epigenetic gene expression profiling identifies frequent disruption of the RELN pathway in pancreatic cancers. Gastroenterology. 2006;130(2):548-65.

25. Stein $T$, Cosimo E, Yu X, Smith PR, Simon R, Cottrell L, et al. Loss of reelin expression in breast cancer is epigenetically controlled and associated with poor prognosis. Am J Pathol. 2010;177(5):2323-33.

26. Serrano-Morales JM, Vazquez-Carretero MD, Peral MJ, Ilundain AA, GarciaMiranda P. Reelin-Dab1 signaling system in human colorectal cancer. Mol Carcinog. 2017;56(2):712-21.

27. Nabil Fikri RM, Norlelawati AT, Nour El-Huda AR, Hanisah MN, Kartini A, Norsidah K, et al. Reelin (RELN) DNA methylation in the peripheral blood of schizophrenia. J Psychiatr Res. 2017;88:28-37.

28. Shifman S, Johannesson M, Bronstein M, Chen SX, Collier DA, Craddock NJ, et al. Genome-wide association identifies a common variant in the reelin gene that increases the risk of schizophrenia only in women. PLoS Genet. 2008;4(2):e28.

29. Wedenoja J, Loukola A, Tuulio-Henriksson A, Paunio T, Ekelund J, Silander K, et al. Replication of linkage on chromosome 7q22 and association of the regional Reelin gene with working memory in schizophrenia families. Mol Psychiatry. 2008;13(7):673-84.

30. Kahler AK, Djurovic S, Kulle B, Jonsson EG, Agartz I, Hall H, et al. Association analysis of schizophrenia on 18 genes involved in neuronal migration: MDGA1 as a new susceptibility gene. Am J Med Genet B Neuropsychiatr Genet. 2008;147B(7):1089-100.

31. Wedenoja J, Tuulio-Henriksson A, Suvisaari J, Loukola A, Paunio T, Partonen T, et al. Replication of association between working memory and Reelin, a potential modifier gene in schizophrenia. Biol Psychiatry. 2010;67(10):983-91.
32. Liu Y, Chen PL, McGrath J, Wolyniec P, Fallin D, Nestadt G, et al. Replication of an association of a common variant in the Reelin gene (RELN) with schizophrenia in Ashkenazi Jewish women. Psychiatr Genet. 2010;20(4): 184-6.

33. Li W, Song $X$, Zhang $H$, Yang $Y$, Jiang $C$, Xiao B, et al. Association study of RELN polymorphisms with schizophrenia in Han Chinese population. Prog Neuro-Psychopharmacol Biol Psychiatry. 2011;35(6):1505-11.

34. Kuang WJ, Sun RF, Zhu YS, Li SB. A new single-nucleotide mutation (rs362719) of the reelin (RELN) gene associated with schizophrenia in female Chinese Han. Genet Mol Res. 2011;10(3):1650-8.

35. Li M, Luo XJ, Xiao X, Shi L, Liu XY, Yin LD, et al. Analysis of common genetic variants identifies RELN as a risk gene for schizophrenia in Chinese population. World J Biol Psychiatry. 2013;14(2):91-9.

36. Zhou Z, Hu Z, Zhang L, Hu Z, Liu H, Liu Z, et al. Identification of RELN variation p.Thr3192Ser in a Chinese family with schizophrenia. Sci Rep. 2016; 6:24327.

37. Luo X, Chen S, Xue L, Chen JH, Shi YW, Zhao H. SNP variation of RELN gene and schizophrenia in a Chinese population: a hospital-based case-control study. Front Genet. 2019;10:175.

38. Li W, Guo X, Xiao S. Evaluating the relationship between reelin gene variants (rs7341475 and rs262355) and schizophrenia: a meta-analysis. Neurosci Lett. 2015:609:42-7.

39. Tueting P, Doueiri MS, Guidotti A, Davis JM, Costa E. Reelin down-regulation in mice and psychosis endophenotypes. Neurosci Biobehav Rev. 2006;30(8): 1065-77.

40. Suzuki K, Nakamura K, Iwata Y, Sekine Y, Kawai M, Sugihara G, et al. Decreased expression of reelin receptor VLDLR in peripheral lymphocytes of drug-naive schizophrenic patients. Schizophr Res. 2008;98(1-3):148-56.

41. Fatemi SH, Reutiman TJ, Folsom TD. Chronic psychotropic drug treatment causes differential expression of Reelin signaling system in frontal cortex of rats. Schizophr Res. 2009;111(1-3):138-52.

42. Fatemi SH, Folsom TD, Reutiman TJ, Novak J, Engel RH. Comparative gene expression study of the chronic exposure to clozapine and haloperidol in rat frontal cortex. Schizophr Res. 2012;134(2-3):211-8.

43. Kay SR, Fiszbein A, Opler LA. The positive and negative syndrome scale (PANSS) for schizophrenia. Schizophr Bull. 1987;13(2):261-76.

44. Zhang X, Ding L, Sandford AJ. Selection of reference genes for gene expression studies in human neutrophils by real-time PCR. BMC Mol Biol. 2005;6:4.

45. Lin $\mathrm{CH}$, Lane HY. Early identification and intervention of schizophrenia: insight from hypotheses of glutamate dysfunction and oxidative stress. Front Psychiatry. 2019;10:93.

46. Lin $\mathrm{CH}$, Chang HT, Chen YJ, Lin CH, Huang CH, Tun R, et al. Distinctively higher plasma G72 protein levels in patients with schizophrenia than in healthy individuals. Mol Psychiatry. 2014;19(6):636-7.

47. Akyol ES, Albayrak Y, Aksoy N, Sahin B, Beyazyuz M, Kuloglu M, et al. Increased serum G72 protein levels in patients with schizophrenia: a potential candidate biomarker. Acta Neuropsychiatr. 2017;29(2):80-6.

\section{Publisher's Note}

Springer Nature remains neutral with regard to jurisdictional claims in published maps and institutional affiliations.

Ready to submit your research? Choose BMC and benefit from:

- fast, convenient online submission

- thorough peer review by experienced researchers in your field

- rapid publication on acceptance

- support for research data, including large and complex data types

- gold Open Access which fosters wider collaboration and increased citations

- maximum visibility for your research: over $100 \mathrm{M}$ website views per year

At $\mathrm{BMC}$, research is always in progress.

Learn more biomedcentral.com/submissions 